\title{
CEO's traits, dynamic compensation and capital structure
}

\author{
Wei Ye $\mathrm{e}^{\mathrm{a}, *}$, Yong Zhang \\ ${ }^{a}$ School of Economics and Trade, Hunan University, Changsha, China. \\ ${ }^{b}$ College of Mathematics and statistics, Jishou University, Jishou, China.
}

\begin{abstract}
This paper studies a model of dynamic compensation and capital structure with managerial traits. We show that Optimistic manager perceives equity as more undervalued than debt, while, confident manager perceives debt as more undervalued than equity. Managerial risk aversion mitigates manager's bias. The risk aversion of the optimistic manager has a convex effect on the optimal coupon. There exists the level of risk aversion eliminating the bias on the leverage. The managerial optimist has an ambiguous effect on the owner's bankruptcy level. The risk aversion has a convex effect on the owner's bankruptcy level. The optimistic/confident manager underestimates the credit spread. The risk aversion has convex effect on the credit spread. In contrast to rational manager, the optimistic/confident manger has higher level of effort. The risk aversion has a negative effect on the effort. Keywords: Managerial triats, Dynamic compensation, capital structure
\end{abstract}

\footnotetext{
The research reported in this paper was supported by the National Natural Science Foundation of China (project NO.71502054).

${ }^{*}$ Corresponding author.

Email addresses: 18973108139@189.cn (Wei Ye), yz0745zy@163.com (Yong Zhang)
} 


\section{Introduction}

Managerial traits affect a corporation's capital structure has been an important issue in corporate finance literature. Optimistic manager overestimates the growth rate of earnings while confident manager underestimates the riskiness of earnings. In other word, optimism creates an upward bias in the mean of distribution while confidence creates an upward bias in it precision. Researchers have extended the psychology literature to behavioral corporate finance and find that managers, as a special group, are more likely to exhibit optimism than ordinary people (Landier and Thesmar (2009)). Bernardo and Welch (2001) shows some managers are confident.

Malmendier and Tate (2005), Malmendier et al. (2007) and Lin et al. (2008) empirically find that confident manager perceives the firm value is undervalued by market. Heaton (2002) develops a two-period model to get these results. Hackbarth (2008) considers a continuous model to get the partially empirical results. For example, Hackbarth (2008) demonstrates in his model that managerial overconfidence is independent of the investment value, the equity is overvalued by market and the optimistic manager need not follow a pecking order theory. These results by Hackbarth (2008) are not consist with some empirical results. Because it maybe the reason that these exits some drawbacks in his model. It can neglect some factors in the fact. such as managerial risk aversion.

To address these and related questions. Managerial risk aversion is considered in this paper, this paper incorporates well-documented managerial traits into a model of dynamic compensation and capital structure. The analysis in the paper extends the study on capital structure with managerial optimism and confidence. We introduce managerial risk aversion to how to have effect on capital structure and related questions.

Our paper examines the capital structure with managerial optimism, confidence and risk aversion in a structural framework. In particular, we extend the model of dynamic compensation and capital structure developed by He (2011) by incorporating managerial traits. While, we also follow the line of Hackbarth (2008) and Hackbarth (2009). Our paper differs from these model in two ways. First, we extend the model of dynamic compensation by introducing managerial traits and study behavioral finance problem. Second, Hackbarth 
(2008) don't consider the managerial risk aversion and compensation, we study interaction these factors and capital structure.

Our paper provides several important results. First, we show that optimistic /confident manager perceives debt as undervalued by market. The result is exactly the same in Hackbarth (2008). While, We also show that optimistic / confident manager perceives equity value as undervalued by market and unleveraged firm value as undervalued by market, which is opposite with Hackbarth (2008). It is consist with Heaton (2002), Malmendier and Tate (2005), Malmendier et al. (2011). Optimistic manager follows a pecking order in this paper, which is not consist with Hackbarth (2008). Managerial risk aversion mitigates manager's bias. In other word, the risk aversion less managerial motive to follow a pecking order.

Second, The managerial optimist/confidence has a positive effect on the optimal coupon. it is the same as Hackbarth (2008). While, we also have that he risk aversion of the optimistic manager has an convex effect on the optimal coupon, and the risk aversion of the confident manager has an negative effect on the optimal coupon. Third, The managerial optimist/confidence has a positive effect on the actual leverage, which is consist with Hackbarth (2008), Hackbarth (2009), Yu et al. (2006), Malmendier et al. (2011). The optimistic manager underestimate the leverage, it is the same as Hackbarth (2008). While, the less risk-aversion and confident manager or the high risk-aversion and confident manager overestimate the leverage, and the intermediate risk-aversion and confident manager overestimate the leverage. These results is not consist with Hackbarth (2008). what's interesting thing that there exists the level of risk aversion eliminating the bias on the leverage. Fourth, the managerial confidence has a positive effect on the owner's bankruptcy level, which is consist with Hackbarth (2008). While, The managerial optimist has an ambiguous effect on the owner's bankruptcy level, the effect is related with the level of risk aversion. The risk aversion has a convex effect on the owner's bankruptcy level. The optimistic manager underestimates the bankruptcy level, which is the same as Hackbarth (2008). For confident manager, the less risk-aversion manager underestimates the bankruptcy level, the the higher risk-aversion manager overestimates the bankruptcy level. Firth, the optimistic/confident manager underestimates the credit spread. the result is the same as Adam et al. (2014). The 
risk aversion has convex effect on the credit spread. Lastly, in contrast to rational manager, the optimistic/confident manger has higher level of effort. The result is consist with Gervais et al. (2002), De la Rosa (2011), Chen and Li (2007), Gervais et al. (2007). The risk aversion has a negative effect on the effort.

The structure of the article is as follows. Section 2 lays out the capital structure framework with managerial traits and dynamic compensation. Section 3 analyzes some analytical and numerical results. Section 4 concludes.

\section{The model}

Following He (2011), we assume a firm hires a manager to operate a business, of which the cash flow $X$ per unit of time depends on its manager's unobservable effort level $a_{t} \in[0, \bar{a}]$ for $t \geq 0$ and some upper bound $\bar{a}>0$ by the following equation:

$$
d X_{t}=\left(\mu+a_{t}\right) X_{t} d t+\sigma X_{t} d B_{t}
$$

where $\mu$ is the baseline growth level, $\sigma>0$ is the instantaneous standard deviation and $d B_{t}$ represents the increment of a standard Brownian motion. The manager has the so-called managerial traits meaning that he is optimistic, confident and risk-averse. More detailedly, we assume the manager with a CARA instantaneous consumption utility, overestimates the growth level and takes it as $\mu^{\prime}>\mu$ while he underestimates the instantaneous standard deviation and take it as $\sigma^{\prime}<\sigma$.

The manager can borrow and save at the risk-free rate $r$ in his personal savings account to smooth his consumption. The account balance, as well as the managerial actual consumption, is unobservable to shareholders and the following contract is therefore signed.

Contracting problem and solution. At the start of hiring the manager, an employment contract $\Pi=\{c ; a\}$ is signed between the manager and shareholders that specifies the managerial recommended consumption process $c$ and the recommended effort process $a$. The process $c$ can also be interpreted as the wage process. Both elements are naturally adapted to the filtration generated by $X$. In other words, they are functions of the managerial performance history. 
Given a contract $\Pi=\{c ; a\}$, the manager chooses his consumption rate $\hat{c}$ and effort level $\hat{a}$ to solve the following optimization problem: ${ }^{1}$

$$
V(\Pi, s, x)=\max _{\left\{\hat{c}_{t}, \hat{a}_{t}\right\}} \mathbb{E}\left[\int_{0}^{\infty} e^{-r t} u\left(\hat{c}_{t}, \hat{a}_{t}\right) d t \mid S_{0}=s, X_{0}=x\right]
$$

subject to

$$
d S_{t}=r S_{t} d t+\left(c_{t}-\hat{c}_{t}\right) d t, \quad d X_{t}=\left(\mu^{\prime}+\hat{a}_{t}\right) X_{t} d t+\sigma^{\prime} X_{t} d B_{t}
$$

where process $S$ represents the manager's saving account balance, the instantaneous utility function $u(z, y)=-\frac{1}{\gamma} e^{-\gamma(z-g(x, y))}$ for $(z, y) \in \mathbb{R}^{+} \times[0, \bar{a}], \gamma$ is the managerial risk-aversion index and the managerial effort cost takes the form $g(x, y)=\frac{\theta}{2} y^{2} x$ for some constant $\theta>0$.

We suppose that shareholders know the managerial traits in advance and the manager has a time- 0 outside option with the value of $v_{0}$. Due to the fact that the manager's decisions on his effort, consumption and saving are unobservable, shareholders therefore need to specify a contract $\Pi=\{c ; a\}$, which solves

$$
J^{U}\left(x, v_{0}\right) \equiv \max _{\Pi} \mathbb{E}\left[\int_{0}^{\infty} e^{-r t}\left(X_{t}-c_{t}\right) d t \mid X_{0}=x\right]
$$

subject to $V(\Pi) \geq v_{0}$.

Definition 2.1. A contract $\Pi=\{c ; a\}$ is incentive-compatible and no-savings if the solution to the optimization problem (2) is $\{c ; a\}$.

According to He (2011), without loss of generality, we consider only the incentivecompatible and no-savings contracts.

Given the contract $\Pi=\{c ; a\}$, the managerial continuation value is defined by

$$
\mathbb{E}\left[\int_{t}^{\infty} e^{-r(s-t)} u\left(c_{s}, a_{s}\right) d s \mid S_{t}=s, X_{t}=x\right],
$$

which is equal to $V(\Pi, s, x)$ thanks to $(2)$ and the time-homogeneous system we discuss here. Let $V_{t} \equiv V\left(\Pi, S_{t}, X_{t}\right)$ and then by the martingale representation theorem, (4) implies that the managerial continuation value evolves as

$$
d V_{t}=r V_{t} d t-u\left(c_{t}, a_{t}\right) d t+\beta_{t}\left(-\gamma r V_{t}\right)\left[d X_{t}-\left(\mu^{\prime}+a_{t}\right) X_{t} d t\right]
$$

\footnotetext{
${ }^{1}$ Following He (2011), we assume all agents discount future cash flows or utility at the constant risk-free interest rate $r$.
} 
where $\beta$ is a progressively measurable process. Due to the CARA utility assumption, the manager's decision on his effort is independent of his saving account balance. Thanks to He (2011), we further have

$$
V\left(\Pi, S_{t}, X_{t}\right)=V_{t}\left(\Pi, 0, X_{t}\right) e^{-\gamma r S_{t}}
$$

Therefore, for simplicity, we assume the managerial initial wealth is 0 in the following text. Letting $V_{t} \equiv V\left(\Pi, 0, X_{t}\right)$, we conclude that

$$
d V_{t}=-\gamma r \theta a_{t} \sigma^{\prime} X_{t} V_{t} d B_{t}
$$

if the contract $\Pi$ is incentive-compatible and no savings. For the proof of its similar form, please refer to He (2011).

\subsection{Pricing the securities of firm and capital structure}

In this subsection, we give the the securities value of firm and capital structure.

Given the state variables $x$ and $V$, the shareholders value function is

$$
J^{U}(x, V)=\max E\left[\int_{t}^{\infty} e^{-r(s-t)}\left(X_{s}-c_{s}\right) \mid X_{t}=x\right],
$$

s.t. $V_{t}(\Pi, x)=V$.

Using the HJB equation for the shareholders' problem in (8) is

$r J^{U}(x, V)=\max _{a \in[0, \bar{a}]}\left\{x-c+(\mu+a) x J_{x}^{U}+\frac{1}{2}(\sigma x)^{2} J_{x x}^{U}-\gamma r \theta a \sigma^{\prime} \sigma V_{t} x^{2} J_{x V}^{U}+\frac{1}{2}\left(\gamma r \theta a \sigma^{\prime} V x\right)^{2} J_{V V}^{U}\right\}$,

The absence of wealth effect, thanks to the CARA preference, leads to the guess of $J^{U}(x, V)=f(x)+\frac{1}{\gamma r} \ln (-\gamma r V)$, so, we have the unlevered firm value in the following theorem.

Theorem 2.1. The unlevered firm value meet the equation

$$
r f(x)=\max _{a \in[0, \bar{a}]}\left\{x+(\mu+a) x f_{x}+\frac{1}{2}(\sigma x)^{2} f_{x x}-\frac{\theta}{2} a^{2} x-\frac{1}{2} \gamma r\left(\theta a \sigma^{\prime} x\right)^{2}\right\},
$$

and the boundary condition $f(0)=0, \lim _{x \rightarrow \infty} f_{x}=\frac{1}{r-\mu}$

The optimal effort as

$$
a_{t}^{*}=\min \left(\frac{f_{x}}{\theta\left(1+\theta \gamma r \sigma^{\prime 2} x\right)}, \bar{a}\right) .
$$


Theorem 2.2. The equity value satisfies the following equation

$$
r E=\max _{a \in[0, \bar{a}]}\left\{x-(1-\tau) C+(\mu+a) x E_{x}+\frac{1}{2}(\sigma x)^{2} E_{x x}-\frac{\theta}{2} a^{2} x-\frac{1}{2} \gamma r\left(\theta a \sigma^{\prime} x\right)^{2}\right\},
$$

and the boundary condition $E\left(x_{b}\right)=0$ and $\lim _{x \rightarrow \infty} E(x)=\frac{x}{r-\mu}+\frac{1}{2(r-\mu)^{2} \theta^{2} \gamma r \sigma^{\prime 2}}-\frac{(1-\tau) C}{r}$, the smooth-pasting condition $E_{x}\left(x_{b}\right)=0$.

The optimal effort as

$$
a_{t}^{*}=\min \left(\frac{E_{x}}{\theta\left(1+\theta \gamma r \sigma^{\prime 2} x\right)}, \bar{a}\right) .
$$

The debt value satisfies

$$
r D=C+\left(\mu+a^{*}\right) x D_{x}+\frac{1}{2}(\sigma x)^{2} D_{x x}
$$

the boundary condition: $D\left(x_{b}\right)=(1-\alpha) f\left(x_{b}\right)$ and $\lim _{x \rightarrow \infty} D(x)=\frac{C}{r}$

The optimal coupon $C^{*}$ satisfies

$$
C^{*}=\arg \max _{C}(E+D)
$$

\section{Numerical results and discussion}

\subsection{Base case parameters}

In our model, we take the following baseline parameter values. Volatility rate $\sigma=$ $25 \%$, interest rate $r=5 \%$, bankruptcy cost $\alpha=25 \%$ and tax rate $\tau=20 \%$ followed as Leland(1998). Risk aversion $\gamma=5$, the growth parameter $\mu=-0.5 \%$ and $\bar{a}=5 \%$ which are used in the He (2011). The effort $\operatorname{cost} \theta=35$, the initial cash flow $x=50$.

In our numerical analysis. We follow the line of Hackbarth (2008), For irrational manager, she/he think that the shareholder trust her/his financing decision based on her/his beliefs $b^{\prime}=\left\{\mu^{\prime}, \sigma^{\prime}\right\}$. So, in manager's perspective, the shareholder beliefs is consist with irrational manager's beliefs. In the table with manager's perspective, we give quantities based on the irrational manager's beliefs $b^{\prime}$, while, in the table with market's perspective, we show quantities based on the market's beliefs $b=\{\mu, \sigma\}$ with the debt coupons are chosen by the irrational manager to maximize firm value. 
Table 1: Managerial belief $(\gamma=3)$

\begin{tabular}{lccccccccc}
\hline & $U$ & $V$ & $L$ & $C$ & $D$ & $E$ & $x_{b}$ & $a^{*}$ & $C R$ \\
\hline$\mu=-0.5 \%$ & 923.48 & 1247.3 & $48.72 \%$ & 33.79 & 607.67 & 639.63 & 10.41 & 0.0296 & 56 \\
$\mu^{\prime}=-0.25 \%$ & 968.18 & 1323.4 & $49.65 \%$ & 36.35 & 657.14 & 666.29 & 10.69 & 0.0310 & 53 \\
$\mu^{\prime}=0 \%$ & 1017.4 & 1408.5 & $50.83 \%$ & 39.44 & 715.94 & 692.53 & 10.07 & 0.0325 & 51 \\
$\sigma=25 \%$ & 923.48 & 1247.3 & $48.72 \%$ & 33.79 & 607.67 & 639.63 & 10.41 & 0.0296 & 56 \\
$\sigma^{\prime}=22.5 \%$ & 926.86 & 1331.1 & $54.77 \%$ & 39.67 & 729.07 & 602.05 & 12.79 & 0.0362 & 44 \\
$\sigma^{\prime}=20 \%$ & 931.58 & 1444.3 & $61.21 \%$ & 47.14 & 884.05 & 560.29 & 15.78 & 0.0456 & 33 \\
\hline
\end{tabular}

Table 2: Market's belief $(\gamma=3)$

\begin{tabular}{lccccccccc}
\hline & $U$ & $V$ & $L$ & $C$ & $D$ & $E$ & $x_{b}$ & $a^{*}$ & $C R$ \\
\hline$\mu=-0.5 \%$ & 923.48 & 1247.3 & $48.72 \%$ & 33.79 & 607.67 & 639.63 & 10.41 & 0.0296 & 56 \\
$\mu^{\prime}=-0.25 \%$ & 923.48 & 1246.3 & $51.51 \%$ & 36.35 & 641.94 & 604.37 & 11.47 & 0.0294 & 66 \\
$\mu^{\prime}=0 \%$ & 923.48 & 1242.2 & $54.68 \%$ & 39.44 & 679.23 & 563.00 & 12.76 & 0.0291 & 81 \\
$\sigma=25 \%$ & 923.48 & 1247.3 & $48.72 \%$ & 33.79 & 607.67 & 639.63 & 10.41 & 0.0296 & 56 \\
$\sigma^{\prime}=22.5 \%$ & 923.48 & 1241.8 & $54.90 \%$ & 39.67 & 681.78 & 559.98 & 12.85 & 0.0291 & 82 \\
$\sigma^{\prime}=20 \%$ & 923.48 & 1220.0 & $61.73 \%$ & 47.14 & 753.09 & 466.91 & 15.94 & 0.0281 & 126 \\
\hline
\end{tabular}

Table 3: Managerial belief $(\gamma=5)$

\begin{tabular}{lccccccccc}
\hline & $U$ & $V$ & $L$ & $C$ & $D$ & $E$ & $x_{b}$ & $a^{*}$ & $C R$ \\
\hline$\mu=-0.5 \%$ & 917.73 & 1133.67 & $39.35 \%$ & 24.50 & 446.05 & 687.62 & 7.98 & 0.0182 & 49 \\
$\mu^{\prime}=-0.25 \%$ & 961.86 & 1199.2 & $40.60 \%$ & 26.65 & 486.91 & 712.25 & 8.33 & 0.0190 & 47 \\
$\mu^{\prime}=0 \%$ & 1010.40 & 1272.20 & $42.05 \%$ & 29.20 & 534.95 & 737.25 & 8.75 & 0.0199 & 46 \\
$\sigma=25 \%$ & 917.73 & 1133.67 & $39.35 \%$ & 24.50 & 446.05 & 687.62 & 7.98 & 0.0182 & 49 \\
$\sigma^{\prime}=22.5 \%$ & 919.75 & 1190.2 & $45.59 \%$ & 29.25 & 542.66 & 647.55 & 10.08 & 0.0223 & 39 \\
$\sigma^{\prime}=20 \%$ & 922.58 & 1268.40 & $53.48 \%$ & 36.02 & 678.36 & 590.06 & 13.13 & 0.0279 & 31 \\
\hline
\end{tabular}


Table 4: Market's belief $(\gamma=5)$

\begin{tabular}{lccccccccc}
\hline & $U$ & $V$ & $L$ & $C$ & $D$ & $E$ & $x_{b}$ & $a^{*}$ & $C R$ \\
\hline$\mu=-0.5 \%$ & 917.73 & 1133.67 & $39.35 \%$ & 24.50 & 446.05 & 687.62 & 7.98 & 0.0182 & 49 \\
$\mu^{\prime}=-0.25 \%$ & 917.73 & 1133.4 & $41.98 \%$ & 26.65 & 475.84 & 657.56 & 8.87 & 0.0181 & 60 \\
$\mu^{\prime}=0 \%$ & 917.73 & 1132.40 & $44.99 \%$ & 29.20 & 509.45 & 622.98 & 9.91 & 0.0179 & 73 \\
$\sigma=25 \%$ & 917.73 & 1133.67 & $39.35 \%$ & 24.50 & 446.05 & 687.62 & 7.98 & 0.0182 & 49 \\
$\sigma^{\prime}=22.5 \%$ & 917.73 & 1132.4 & $45.04 \%$ & 29.25 & 510.08 & 622.31 & 9.93 & 0.0179 & 73 \\
$\sigma^{\prime}=20 \%$ & 917.73 & 1126.6 & $52.43 \%$ & 36.02 & 590.72 & 535.88 & 12.67 & 0.0175 & 110 \\
\hline
\end{tabular}

Table 5: Managerial belief $(\gamma=7)$

\begin{tabular}{lccccccccc}
\hline & $U$ & $V$ & $L$ & $C$ & $D$ & $E$ & $x_{b}$ & $a^{*}$ & $C R$ \\
\hline$\mu=-0.5 \%$ & 915.26 & 1082.8 & $43.64 \%$ & 27.68 & 472.53 & 610.25 & 9.82 & 0.0129 & 86 \\
$\mu^{\prime}=-0.25 \%$ & 959.15 & 1142.5 & $43.93 \%$ & 29.10 & 501.93 & 640.56 & 9.92 & 0.0135 & 80 \\
$\mu^{\prime}=0 \%$ & 1007.5 & 1208.9 & $43.40 \%$ & 29.93 & 524.64 & 684.28 & 9.72 & 0.0142 & 70 \\
$\sigma=25 \%$ & 915.26 & 1082.8 & $43.64 \%$ & 27.68 & 472.53 & 610.25 & 9.82 & 0.0129 & 86 \\
$\sigma^{\prime}=22.5 \%$ & 916.71 & 1123.3 & $45.39 \%$ & 28.47 & 509.82 & 613.49 & 10.55 & 0.0159 & 58 \\
$\sigma^{\prime}=20 \%$ & 918.73 & 1181.2 & $48.71 \%$ & 30.83 & 575.32 & 605.91 & 11.85 & 0.0202 & 36 \\
\hline
\end{tabular}

Table 6: Market's belief $(\gamma=7)$

\begin{tabular}{lccccccccc}
\hline & $U$ & $V$ & $L$ & $C$ & $D$ & $E$ & $x_{b}$ & $a^{*}$ & $C R$ \\
\hline$\mu=-0.5 \%$ & 915.26 & 1082.8 & $43.64 \%$ & 27.68 & 472.53 & 610.25 & 9.82 & 0.0129 & 86 \\
$\mu^{\prime}=-0.25 \%$ & 915.26 & 1082.7 & $45.32 \%$ & 29.10 & 490.64 & 592.04 & 10.40 & 0.0128 & 93 \\
$\mu^{\prime}=0 \%$ & 915.26 & 1082.6 & $46.28 \%$ & 29.93 & 500.99 & 581.57 & 10.73 & 0.0128 & 97 \\
$\sigma=25 \%$ & 915.26 & 1082.8 & $43.64 \%$ & 27.68 & 472.53 & 610.25 & 9.82 & 0.0129 & 86 \\
$\sigma^{\prime}=22.5 \%$ & 915.26 & 1082.7 & $44.58 \%$ & 28.47 & 482.68 & 600.06 & 10.15 & 0.0128 & 90 \\
$\sigma^{\prime}=20 \%$ & 915.26 & 1082.3 & $50.83 \%$ & 30.83 & 511.99 & 570.34 & 10.09 & 0.0127 & 102 \\
\hline
\end{tabular}




\subsection{Pecking order theory and managerial traits}

Result 1. Optimistic/confident manager perceives debt and equity as undervalued. Optimistic manager perceives equity as more undervalued than debt, while, confident manager perceives debt as more undervalued than equity. Managerial risk aversion mitigates manager's bias.

In the table 1, 2, for the unlevered firm value, optimistic manager $\left(\mu^{\prime}=0 \%\right)$ believes that the firm value is undervalued by 93.92, and confident manager $\left(\sigma^{\prime}=20 \%\right)$ believes that the firm value is undervalued by 8.1. For levered firm, optimistic manager $\left(\mu^{\prime}=\right.$ 0 ) believes that debt value is undervalued by 36.71, and equity value is undervalued by 129.53. Confident manager $\left(\sigma^{\prime}=0.2\right)$ believes that debt value is undervalued by 130.96 , and equity value is undervalued by 94.38 . So, optimistic/confident manager perceives firm securities value is undervalued by market. The result is consist with Malmendier et al. (2007) and Malmendier et al. (2011), Heaton (2002). While Hackbarth (2008) indicates the optimistic/confident manager think the equity value is overvalued by market and confident manager think the unlevered firm value is consist with market. His result is not consist with our result. Hackbarth (2008) don't consider the managerial risk aversion, while, we incorporate it into the pricing.

In table 3-6, when $\gamma=5(7)$ and the manager is optimistic $\left(\mu^{\prime}=0 \%\right)$, for the unlevered firm, the value is undervalued by 92.67 (92.24). For the levered firm, the debt value is undervalued by 25.50 (23.65), and the equity value is undervalued by 114.27 (102.71). So, The degree of optimistic manager's bias is negative with risk aversion. when $\gamma=5(7)$ and the manager is confident $\left(\sigma^{\prime}=20 \%\right)$, for the unlevered firm, the value is undervalued by 4.85 (3.47). For the levered firm, the debt value is undervalued by 87.64 (63.33), and the equity value is undervalued by $54.18(35.57)$. So, The degree of confident manager's bias is negative with risk aversion.

The optimistic manager perceives equity as more undervalued than debt, So, the optimistic manager prefer the debt financing to equity financing, it follows a pecking order theory, it is consist with Adam et al. (2014). But, the confident manager perceives debt as 
more undervalued than equity. In contrast to previous contributions, it therefore need not follow a pecking order theory, which is consist with Hackbarth (2008).

\section{3. capital structure and managerial traits}

\subsection{1. optimal coupon and managerial traits}

Result 2. The managerial optimist/confidence has a positive effect on the optimal coupon. While, The risk aversion of the optimistic manager has an convex effect on the optimal coupon, and the risk aversion of the confident manager has an negative effect on the optimal coupon.

In table 3 and table 4 , when the optimistic manager belief is $\mu^{\prime}=-0.25 \%(0 \%)$, the level of optimal coupon is 26.65 (29.20). when the confident manager belief is $\sigma^{\prime}=22.5 \%(20 \%)$, the level of optimal coupon is 29.25(36.02). The result is consist with Hackbarth (2008) and Hackbarth (2009). When the manager is optimistic $\left(\mu^{\prime}=(0 \%)\right)$, the optimal coupon is $39.44(29.20 / 29.93)$ with risk aversion $\gamma=3(5 / 7)$; when the manager is optimistic $\left(\sigma^{\prime}=20 \%\right)$, the optimal coupon is $47.14(36.02 / 30.83)$ with risk aversion $\gamma=3(5 / 7)$. When the risk aversion of the optimistic manager is higher or lower, the coupon is higher, the risk aversion is intermediate, the optimal coupon is smaller. While, the optimal coupon decreases with the risk aversion of confident manager.

\subsubsection{Leverage and managerial traits}

Result 3. The managerial optimist/confidence has a positive effect on the actual leverage. The optimistic manager underestimate the leverage, while, the less risk-aversion and confident manager or the high risk-aversion and confident manager overestimate the leverage, and the intermediate risk-aversion and confident manager overestimate the leverage. there exists the level of risk aversion eliminating the bias on the leverage.

In table 3 and table 4 , when the $\mu^{\prime}=-0.25 \%(0 \%)$, the actual leverage is $41.98 \%(44.99 \%)$; when the $\sigma^{\prime}=22.5 \%(20 \%)$, the actual leverage is $45.04 \%$ (52.43\%). it is consist with Hackbarth (2008). When the risk aversion $\gamma=3(5 / 7)$, the optimistic managerial $\left(\mu^{\prime}=0 \%\right)$ perceived leverage is $50.83 \%(42.05 \% / 43.40 \%)$, the actual leverage is $54.68 \%(44.99 \% / 46.28 \%)$. 
On the one hand, the risk aversion of optimistic manager has a convex effect on the perceived (actual) leverage; on the other hand, the optimistic manager underestimates the leverage and the risk aversion mitigate the bias. When the risk aversion $\gamma=3(5 / 7)$, the confident managerial $\left(\sigma^{\prime}=20 \%\right)$ perceived leverage is $61.21 \%(53.48 \% / 48.71 \%)$, the actual leverage is $61.73 \%(52.43 \% / 50.83 \%)$. For confident manager, it can get some interesting conclusions. Firstly, the risk aversion has a negative effect on the perceived (actual) leverage. Secondly, the less risk-aversion and confident manager and the higher risk-aversion and confident manager underestimate the leverage, the intermediate risk-aversion overestimates the leverage. What's more, by the second conclusion, there exists the level of risk aversion eliminating the bias on the leverage.

\subsubsection{Bankruptcy level and managerial traits}

Result 4. The managerial optimist has an ambiguous effect on the owner's bankruptcy level, and the managerial confidence has a positive effect on the owner's bankruptcy level. The risk aversion has a convex effect on the owner's bankruptcy level. The optimistic manager underestimates the bankruptcy level, the less risk-aversion and confident manager underestimates the bankruptcy level, the the higher risk-aversion and confident manager overestimates the bankruptcy level.

When the risk aversion $\gamma=3$, the bankruptcy level of optimistic manager is 10.69 (10.07); When the risk aversion $\gamma=7$, the bankruptcy level of optimistic manager is 9.92(9.72); When the risk aversion $\gamma=5$, the bankruptcy level of optimistic manager is 8.33 (8.75). The managerial optimist has an ambiguous effect on the owner's bankruptcy level. In table 1 , the bankruptcy level is $12.79(15.78)$. the managerial confidence has a positive effect on the owner's bankruptcy level. For optimistic manager $\left(\mu^{\prime}=0 \%\right)$, when the risk aversion $\gamma=3(5 / 7 / 9)$, the bankruptcy level is 10.07 (8.75/9.72); for confident manager $\left(\sigma^{\prime}=20 \%\right)$, the bankruptcy level is $15.78(13.13 / 11.85 / 12.44)$. The risk aversion has a convex effect on the owner's bankruptcy level. In table 3 and table 4 , when the $\left(\mu^{\prime}=0 \%\right)$, the owner's (market) bankruptcy level is 8.75 (9.91). The optimistic manager underestimates the bankruptcy level. When risk aversion $\gamma=3$, the $\left(\sigma^{\prime}=20 \%\right)$, the owner's (market) bankruptcy level is 15.78 
(15.94). When risk aversion $\gamma=5$, the $\left(\sigma^{\prime}=20 \%\right)$, the owner's (market) bankruptcy level is 13.13 (12.67). The less risk-aversion and confident manager underestimates the bankruptcy level, the the higher risk-aversion and confident manager overestimates the bankruptcy level.

\subsubsection{Credit spread and managerial traits}

Result 5. The optimistic/confident manager underestimates the credit spread. The risk aversion has convex effect on the credit spread.

In table $4, \mu^{\prime}=-0.25 \%(0 \%)$, the perceived credit spread is $47 \mathrm{bps}(46 \mathrm{bps})$, the actual credit spread is 60bps (73bps); $\sigma^{\prime}=22.5 \%(20 \%)$, the perceived credit spread is 39bps (31bps), the actual credit spread is 73bps (110bps). The optimistic/confident manager underestimates the credit spread. it is consist with Adam et al. (2014). When $\mu^{\prime}=-0.25 \%$, the risk aversion $\gamma=3(5 / 7)$, the actual credit spread is 66bps (60bps/93bps); When $\sigma^{\prime}=22.5 \%$, the risk aversion $\gamma=3(5 / 7)$, the actual credit spread is $82 \mathrm{bps}$ (73bps/90bps). The risk aversion has convex effect on the credit spread.

\subsection{Managerial effort and managerial traits}

Result 6. In contrast to rational manager, the optimistic/confident manger has higher level of effort. The risk aversion has a negative effect on the effort.

In table 3 and table 4 , when the $\mu^{\prime}=0 \%$, the level of optimistic managerial effort is 0.0190 , and the level of rational managerial effort is 0.0179 ; when the $\sigma^{\prime}=20 \%$, the level of confident managerial effort is 0.0279 , and the level of rational managerial effort is 0.0175. it is consist with De la Rosa (2011), Chen and Li (2007) and Ye and Yuan (2008). when $\mu^{\prime}=0 \%$, the risk aversion $\gamma=3(5 / 7)$, the level of managerial effort is 0.0325 $(0.0199 / 0.0142)$. when $\sigma^{\prime}=20 \%$, the risk aversion $\gamma=3(5 / 7)$, the level of managerial effort is $0.0456(0.0279 / 0.0202)$. The risk aversion has a negative effect on the effort.

\section{Conclusion}

This paper examines the impact of managerial optimism, confidence and risk aversion on the capital structure, peaking order theory and managerial welfare. The model developed 
here demonstrates that Optimistic manager perceives equity as more undervalued than debt, while, confident manager perceives debt as more undervalued than equity. The managerial optimist has an ambiguous effect on the owner's bankruptcy level. The optimistic/confident manager underestimates the credit spread.

This paper introduces the risk aversion into our model. We can show that optimistic manager follows a pecking order, which is consist with previous empirical result. In this paper, we find that the managerial risk aversion have an important impact on capital structure. Managerial risk aversion mitigates manager's bias on firm value. The risk aversion of the optimistic manager has an convex effect on the optimal coupon. There exists the level of risk aversion eliminating the bias on the leverage. The risk aversion has a convex effect on the owner's bankruptcy level. The risk aversion has convex effect on the credit spread.

From behaviorial finance, our paper study that managerial effort and welfare on managerial traits. In contrast to rational manager, the optimistic/confident manger has higher level of effort. The risk aversion has a negative effect on the effort.

In addition, in our model, we consider the capital structure with equity and straight bond. The capital structure can be made up straight bond, junk bond and equity. it may explain why the straight bond is not replaced by junk bond. Kamoto (2014) consider impacts of internal financing on investment decision with managerial traits. Based our model, it can study the investment with managerial traits and the investment cost can be raised by internal cash, equity and bond. it can explore if the firm follows a peaking order. These will be a promising and significant avenue for future research.

\section{References}

Adam, T., Burg, V., Scheinert, T., Streitz, D., 2014. Managerial optimism and debt contract design.

Bernardo, A. E., Welch, I., 2001. On the evolution of overconfidence and entrepreneurs. Journal of Economics \& Management Strategy 10 (3), 301-330. 
Chen, Q., Li, X., 2007. A model on agent-principal relationship with overconfident agents. Journal of Management Engineering [in Chinese] 1, 110-116.

De la Rosa, L. E., 2011. Overconfidence and moral hazard. Games and Economic Behavior $73(2), 429-451$.

Gervais, S., Heaton, J., Odean, T., 2002. The positive role of overconfidence and optimism in investment policy.

Gervais, S., Heaton, J., Odean, T., 2007. Overconfidence, investment policy, and manager welfare. Working paper.

Hackbarth, D., 2008. Managerial traits and capital structure decisions. Journal of Financial and Quantitative Analysis 43 (04), 843-881.

Hackbarth, D., 2009. Determinants of corporate borrowing: A behavioral perspective. Journal of Corporate Finance 15 (4), 389-411.

He, Z., 2011. A model of dynamic compensation and capital structure. Journal of Financial Economics 100 (2), 351-366.

Heaton, J. B., 2002. Managerial optimism and corporate finance. Financial management, 33-45.

Kamoto, S., 2014. Impacts of internal financing on investment decisions by optimistic and overconfident managers. European Financial Management 20 (1), 107-125.

Landier, A., Thesmar, D., 2009. Financial contracting with optimistic entrepreneurs. Review of financial studies $22(1), 117-150$.

Lin, Y., Hu, S., Chen, M., 2008. Testing pecking order prediction from the viewpoint of managerial optimism: Some empirical evidence from taiwan. Pacific-Basin Finance Journal $16(1), 160-181$.

Malmendier, U., Tate, G., 2005. Ceo overconfidence and corporate investment. The journal of finance 60 (6), 2661-2700. 
Malmendier, U., Tate, G., Yan, J., 2007. Corporate financial policies with overconfident managers. Tech. rep., National Bureau of Economic Research.

Malmendier, U., Tate, G., Yan, J., 2011. Overconfidence and early-life experiences: the effect of managerial traits on corporate financial policies. The Journal of finance 66 (5), $1687-1733$.

Ye, B., Yuan, J., 2008. Firm value, managerial confidence, and investments: The case of china. Journal of Leadership Studies 2 (3), 26-36.

Yu, M., Xia, X., Zou, Z., 2006. The relationship between managers' overconfidence and enterprises' radical behavior in incurring debts. Management world [in Chinese] 8, 358379. 